\title{
A Suggested Model to Simulate the Distance Between Signalized Intersection and U-turn on Urban Road (Study Case: Middle East Ring Road, Surabaya)
}

\author{
Muhammad Hadid $^{1 *}$, Wahju Herijanto ${ }^{2}$, Hera Widyastuti ${ }^{3}$ \\ ${ }^{1}$ Civil Engineering Department, Institut Teknologi Kalimantan \\ ${ }^{2}$ Civil Engineering Department, Institut Teknologi Sepuluh Nopember \\ ${ }^{3}$ Civil Engineering Department, Institut Teknologi Sepuluh Nopember \\ *Corresponding author: hadid@itk.ac.id
}

\begin{abstract}
U-turn movement possible generates queueing on U-turn system. Queueing which occurs near intersection could affects to intersection performance. The intersection performance that influenced is speed of vehicle to pass the intersection. The impact is interlock of intersection movement possibly occur. The objective of the research is to determine minimum distance of U-turn and intersection based on Poisson Process Simulation. Location of this research is U-turn on Surabaya, Indonesia with distance from the nearest intersection about 202 meters. Queueing will occur when arrival time of vehicle from intersection is above of total arrival time and service time of vehicle from U-turn. The result of simulation is total queuing cause of operational U-turn about 10 vehicles or 60 meters. The reduction distance of U-turn and Intersection is 142 meters, and it's still fulfil the requirement of regulation about the distance between opening and intersection.
\end{abstract}

Keywords-Poisson Process, Simulation, U-turn, Intersection, Queueing.

\section{INTRODUCTION}

$\mathrm{T}_{1}$ ransportation problem for metropolitan city is congestion problem. Congestion could be occurred on several sections of road such as, intersection, roundabout, U-turn, etc. Planning should considers some determinant factors when locate road facilities, in order it not distrubs traffic. Espessialy U-turn, there are 2 (two) types of U-turn, which are unprotected U-turn and protected one. UnProtected U-turn means the lane for Uturn is mixed with main traffic. And the other hand, Protected U-turn has storage lane to accomodate vehicle that use U-turn. Location of U-turn divided into 2 types, wich are U-turn near intersection and U-turn far from intersection. Further study is needed to identify turn around behavior of vehicle from U-turn near intersection.

U-turn is a road facility that used to change direction of vehicle on divided road. There are 3 (three) steps of Uturn movement [1]. The first step is car decelerate the speed and turn to right lane. Second step is car doing turn around toward opposite way. Third step is car follows the traffic, there is interaction between car which doing $\mathrm{U}$ movement and traffic. The movement after U-turn is depends on driver ability to doing manouver. U-turn activity possible causes queueing on destination flow. If traffic of U-turn is high, the congestion possibly occur. U-turn movement effect queueing on opposite way. If Uturn has high traffic, congestion is possible occur. When the location of U-turn is near with intersection facility it may be effect to performance of intersection.

The problems of this research are how get length of queueing cause of U-turn activity and evaluate U-turn location. Teh This research has limit on how to determine the queueing length based Poisson Process and minimum distance between U-turn and intersection. Poisson process is used to simulate the queueing based on arrival rate from U-turn and intersection. Random number is used to modeling of service time based on service time data. Random number also used to determine arrival car from U-turn and intersection. By evaluate arrival time of car from U-turn and intersection, the queueing length of car from intersection cause of Uturn activity can be determined.

The location of study is U-turn at MERR (Middle East Ring Road) of Surabaya. There are U-turn facility at MERR with high traffic and the distance from intersection is about 201 meters. With this condition, queueing couse of U-turn activity possibly occur. Location of study shown by Figure 1 below. 


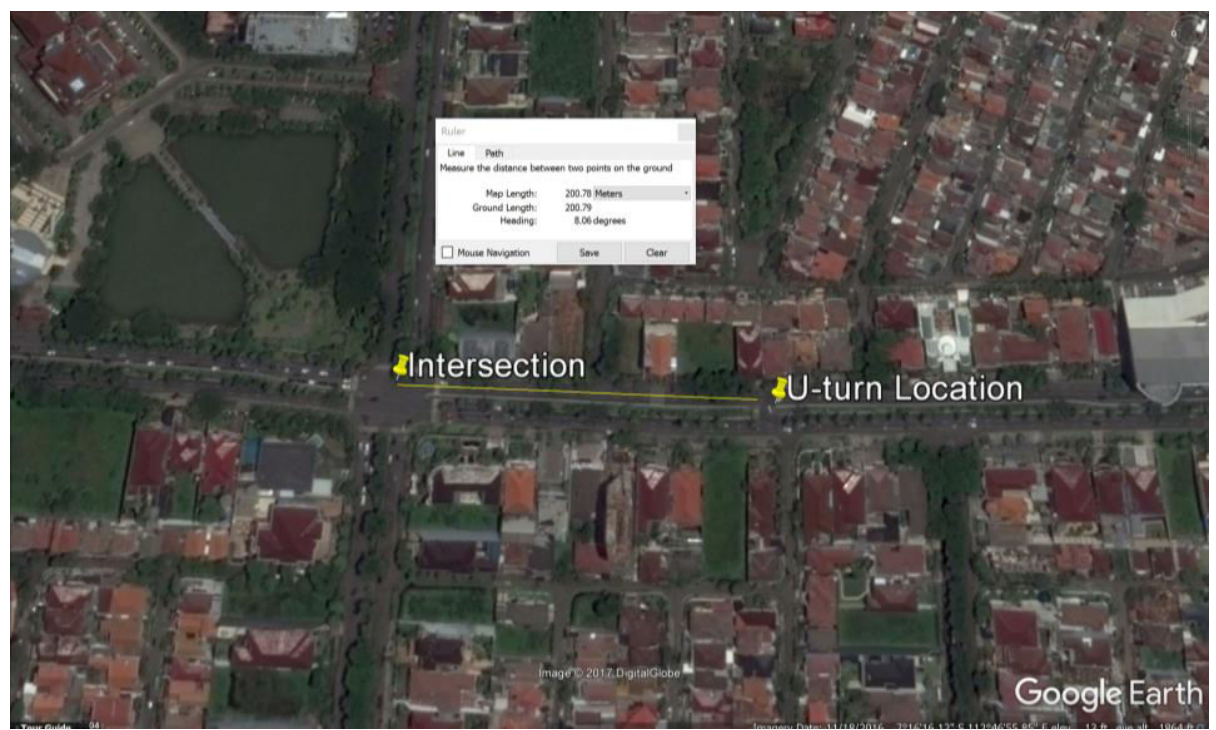

Figure 1. Figure 1. Location and distance between U-turn and intersection

Table 1. Minimum Distance Between Openings (Bina Marga, 1990)

\begin{tabular}{clc}
\hline No & Description & Minimum Distance \\
\hline 1 & Normal Turn Around & $500 \mathrm{~m}$ \\
2 & With right turn lane from intersection & $100 \mathrm{~m}$ \\
3 & Region with low development & $1,000 \mathrm{~m}$ \\
\hline
\end{tabular}

There are several previous researches about using Poisson Process to simulate queueing. Hadid et. al (2014) use Poisson Process to simulate queueing on Uturn. The result of the research shown similarity the length of queueing car from simulation with real condition. The deviation of the result is about $7.69 \%$ from real condition. Another research by Hadid et. al (2014) is study of queueing on U-turn and the impact to single weaving performance at Middle East Ring Road Surabaya. the queueing length is gained by using Poisson Process. The result is queueing length is 102 meters with correction factor $0.9 \mathrm{~s}$ for each car. Hadid et. al (2016) determined queueing length and storage lane for U-turn using Poisson Process. There are 3 (three) locations at Middle East Ring Road (MERR) Surabaya that be object study such as, U-turn Pandugo, U-turn Nirwana and Uturn Galaxy. Simulation uses model of service time, queueing length. The lenght of queueing based on simulation are 150 meter (corresction factor $0.96 \mathrm{~s}$ each car) for U-turn Pandugo, 102 meter (correction factor $0.85 \mathrm{~s}$ each car) for U-turn Nirwana and 114 meter (correction factor $0.95 \mathrm{~s}$ each car) for U-turn Galaxy. Poisson Process is used by Hadid (2016) to simulate queueing car impact from pelican crossing and determine distance pelican crossing and intersection. Determining of the distance is depands on queueing length. The first step is generate crossing model based on intergreen data in real condition. The result is queueing length is 8 (eight) cars or equal with 48 meters. Minimal distance pelican and near intersection is 300 meter. Consider queueing length, the distance pelican crossing and intersection is should be 348 meters. Based on previous studies about Poisson Process, this research is also using Poisson Process to determine queueing length impact of U-turn activity.
The objective of this research is to determine minimum distance between U-turn and intersection depending queueing length and regulation. For regulation about minimum distance between U-turn facility and intersection is refer to Procedures of Separator Design No. 014/T/BNKT/1990 by Directorate General of Bina Marga. The minimum distance is shown by Table $\mathbf{1}$. This research might can support on determing location of road facilities.

\section{METHOD}

\section{A. Poisson Process}

Poisson process can uses to many IID simulation of interarrival time. In this research Poisson Process is used to generate arrival car from U-turn and intersection based on random number. The equation for generating arrival time of car is:

$$
t_{i}=t_{i-1}-(1 / \lambda) \cdot \ln U
$$

\section{Where:}

ti : arrival time of car $(\mathrm{sec})$

ti-1 : arrival time of previous car $(\mathrm{sec})$

$\lambda \quad$ : arrival rate $(\mathrm{car} / \mathrm{sec})$

$\mathrm{U} \quad$ : random number $(0<\mathrm{U} \leq 1)$

Arrival rate $\lambda$ is gained by survey on location of study. There are 2 (two) arrival rate as follow:

1. Arrival rate $\lambda$ of car from U-turn is 1,458 vehicle/hour or 0.202 vehicle/seconds (Hadid et. al, 2016)

2. Arrival rate $\lambda$ of car from intersection is 1,652 vehicle/hour or 0.229 vehicle/seconds 


\section{B. Service Time Modeling}

The model of U-turn service time that used in this research based on previous research of Hadid et. al (2014). The first step to get model is obtain service time data each car which use U-turn. Service time that collect is when the car start doing $\mathrm{U}$ movement until the car follow the traffic perfectly. The second step is using cumulative frequency diagram to get model of service time. The model of service time which used in this research from previous reserach of Hadid et. al (2014) shown on Figure 2 below.

$$
\begin{array}{ll}
x & : \text { Random Number }(0<\mathrm{x} \leq 1) \\
e & : \text { exponential }
\end{array}
$$

\section{Conditions of Simulation}

The first step before simulation is describe the conditions of simulation. There are 7 (seven) conditions of the simulation:

1. The simulation is based on arrival rate of car from U-turn and intersection;

2. U-turn movement using 2 lane on opposite way

3. Queueing is on lane 1 and lane 2

4. Using lane 1 or 2 is decided by random number ( 1

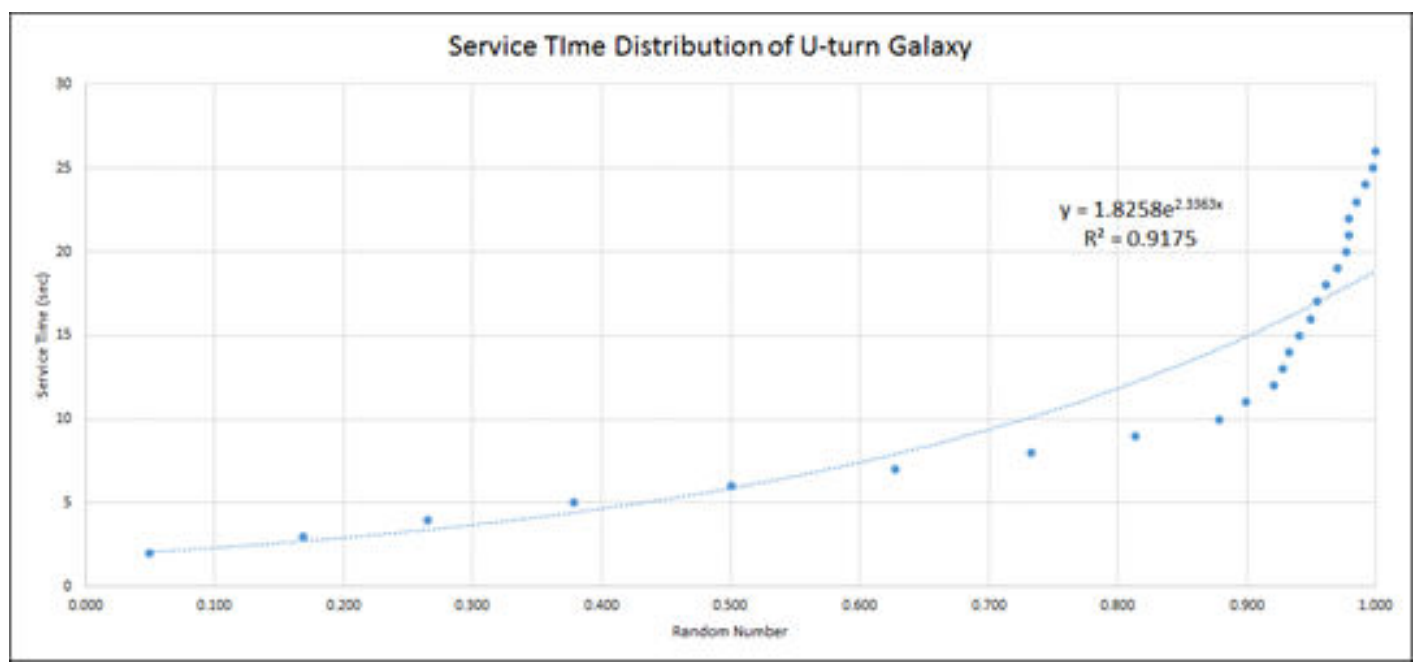

Figure 2. Galaxy U-turn Service Time Distribution. Hadid et. al (2014)

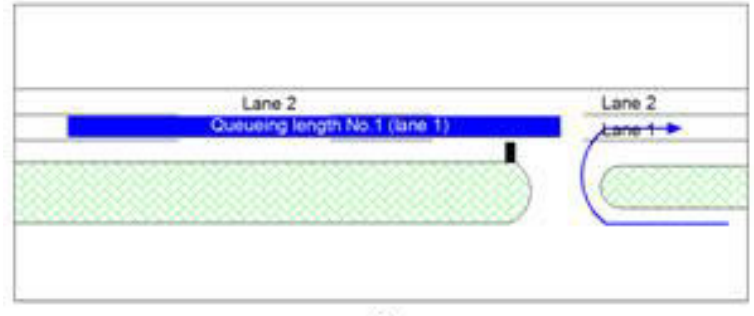

(a)

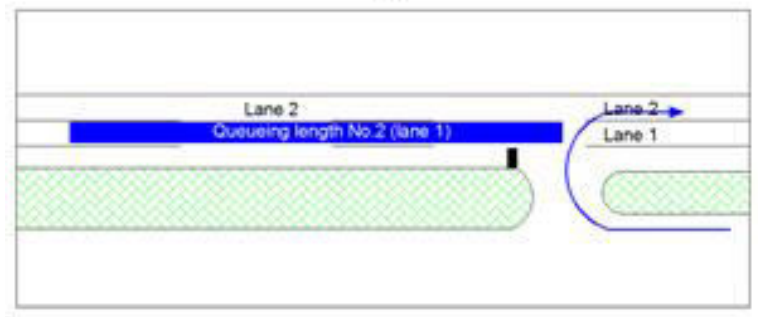

(e)

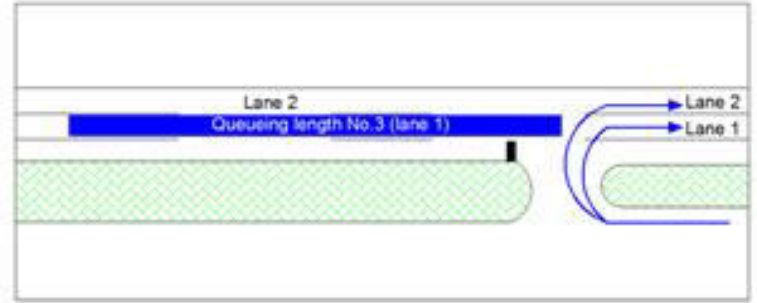

(c)

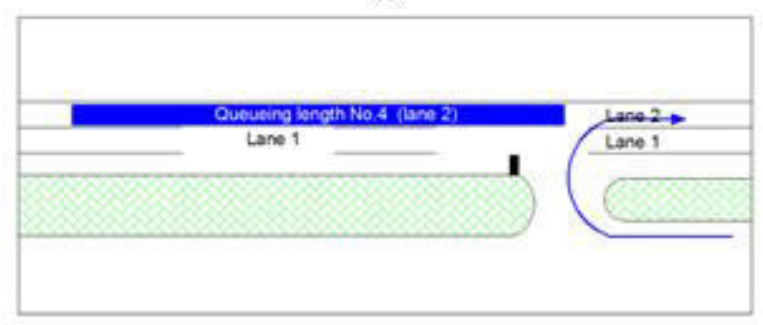

(d)

Figure 3. Simulation of Queueing Length: (a) Queueing on lane1 cause using of lane 1 of U turn; (b) Queueing on lane1 cause using of lane 2 of $U$ turn; (c) Queueing on lane 1 cause using of lane 1 and 2 of $U$ turn; (d) Queueing on lane 2 cause using lane 2 of U-turn

From figure above, the model of service time at U-turn Galaxy is exponential equation is:

$$
y=1.8258 \cdot e^{2.3363 X}
$$

Where:

$y \quad$ : service time $(\mathrm{sec})$ or 2)

5. Stop and go of car is based on gap acceptance, 20 meter for U-turn, 10 meter for main traffic

6. If gap acceptance is not fulfilled, the queueing is occured.

7. The queueing is occur on lane 1 and 2 when the car using lane 2 to doing $\mathrm{U}$ movement 
8. The queueing is occur on lane 1 when the car using lane 1 to doing $\mathrm{U}$ movement

\section{RESULTS AND DISCUSSION}

Car which doing $\mathrm{U}$ movement possibly use lane 1 or lane 2. So that, there are 4 (four) results of simulation of queueing length.

1. Queueing on lane 1 cause using of lane 1 of $U$ turn

2. Queueing on lane1 cause using of lane 2 of $U$ turn

3. Queueing on lane 1 cause using of lane 1 and 2 of U turn

4. Queueing on lane 2 cause using lane 2 of U-turn

The condition above is shown by Figure 3 .

A. Queueing on lane 1 cause using of lane 1 of $U$-turn This condition is occurs when car using lane 1 to $U$ movement Figure 3.a. The Queueing is not distrubt traffic on lane 2. Simulation process is for 1 hour and the graph of queueing shown by Figure 4.From Figure 4 shown that maximum queueing is 8 car or equal with 48 meter. It occurs at $1,902^{\text {nd }}$ seconds and $1906^{\text {th }}$ seconds.

\section{B. Queueing on lane 1 cause using of lane 2 of U-turn}

This condition occur when car using lane 2 to $U$ movement Figure 3.b. Simulation is for 1 hour and the graph of queueing shown by Figure 5. From Figure 5 shown that maximum queueing is 9 car or equal with 54 meter. It occurs at $340^{\text {th }}$ seconds.

\section{Queueing on lane 1 cause using of lane 1 and 2 of U-turn}

This condition is combination section $\mathrm{A}$ and $\mathrm{B}$ above. So that, the result is combination of 2 previous condition. Which mean, the maximum length of queueing is 9 cars or equal with 54 meters at $340^{\text {th }}$ second. The graph of queueing is shown by Figure 6 .

D. Queueing on lane 2 cause using of lane 2 of $U$-turn

When car using lane 2 to turning, traffic on lane 2 is distrub. The impact is queueing possible to occur. By simulation based on condition section II.c is gained result that shown by Figure 7. Basen on Figure 7 the maximum length of queueing is $10 \mathrm{car}$ or equal with 60 meter. The maximum queueing is occred at $1776^{\text {th }}$ seconds.

\section{E. Distance evaluation}

Based on result of simulation, the maximum length of queueing is 60 meter or equal with 10 cars. From Table 1 above the minimal distance between U-turn and intersection is 100 meter. The distance between U-turn Galaxy and intersection is 202 meter (Figure 1). Consider the length of queueing is 60 meter, the distance is reduce from 202 meter into 142 meter. That is still fulfill the requirement about

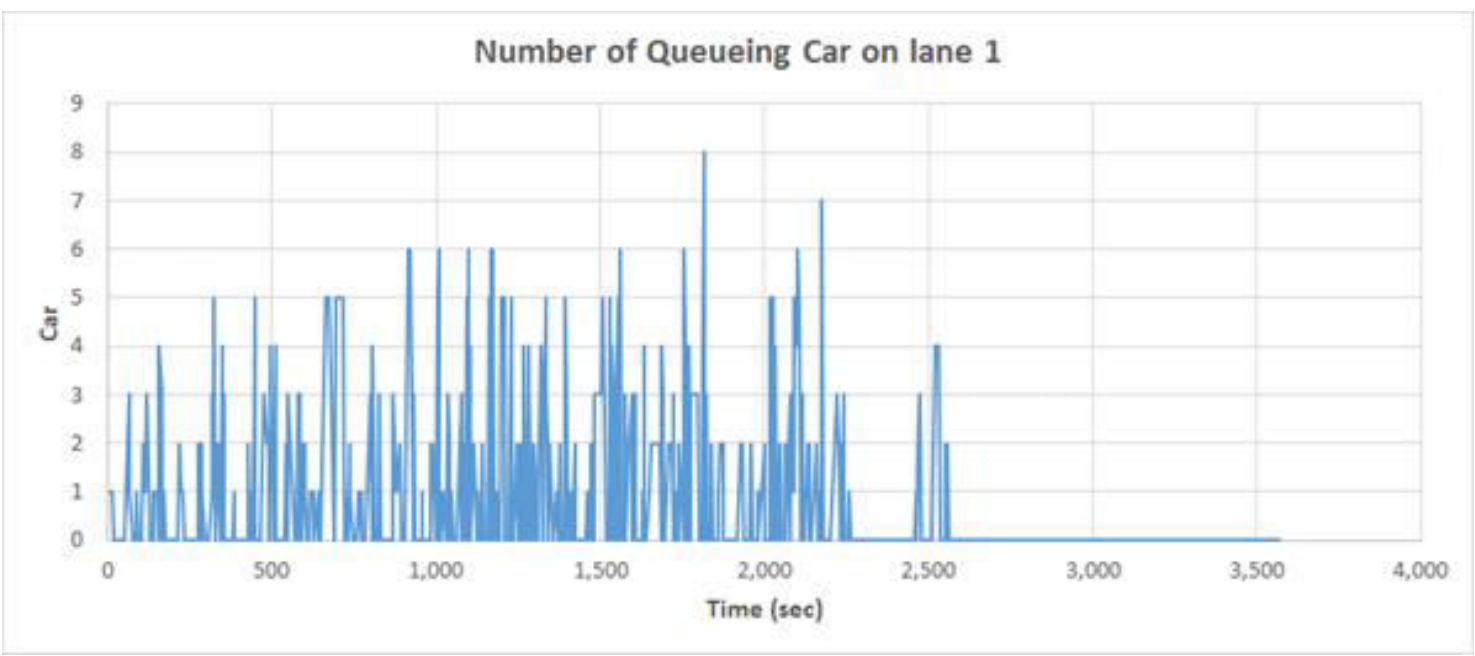

Figure 4. Graph of Queueing on lane1 cause using of lane 1 of U turn

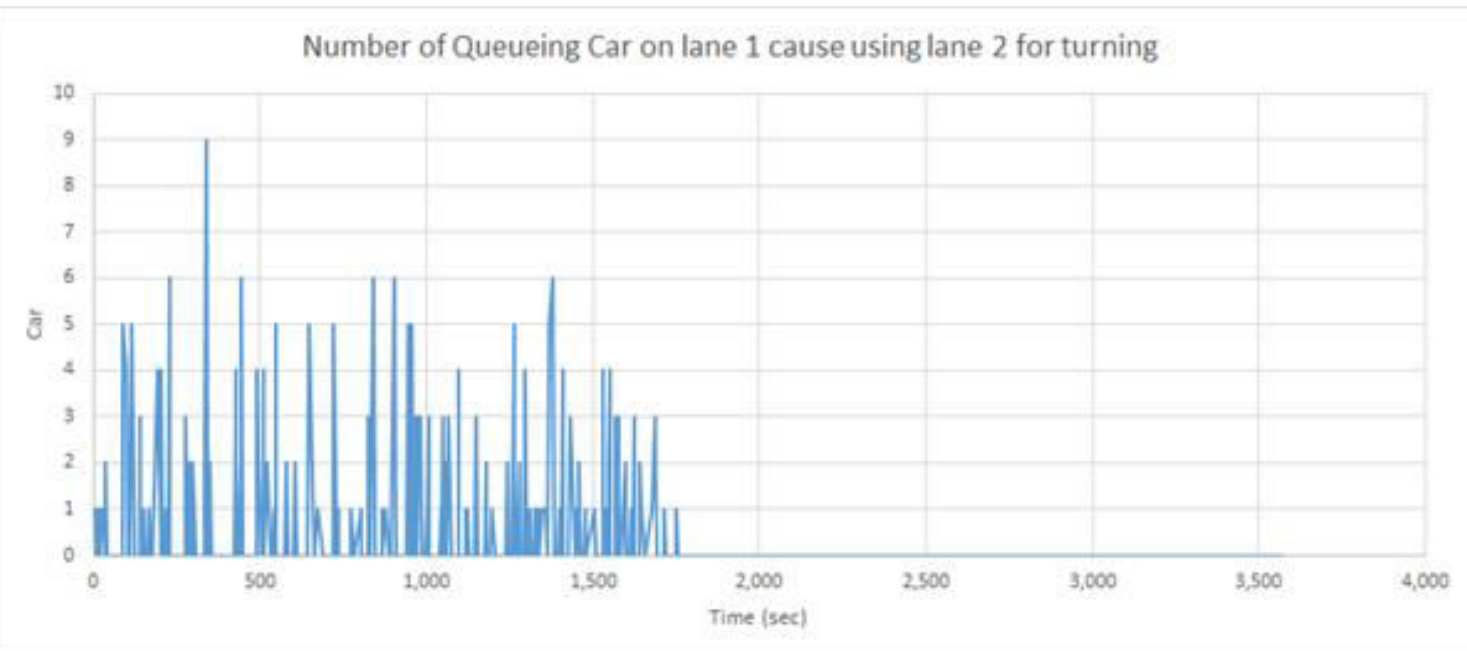

Figure 5. Grpah of Queueing on lane1 cause using of lane 2 of U turn 


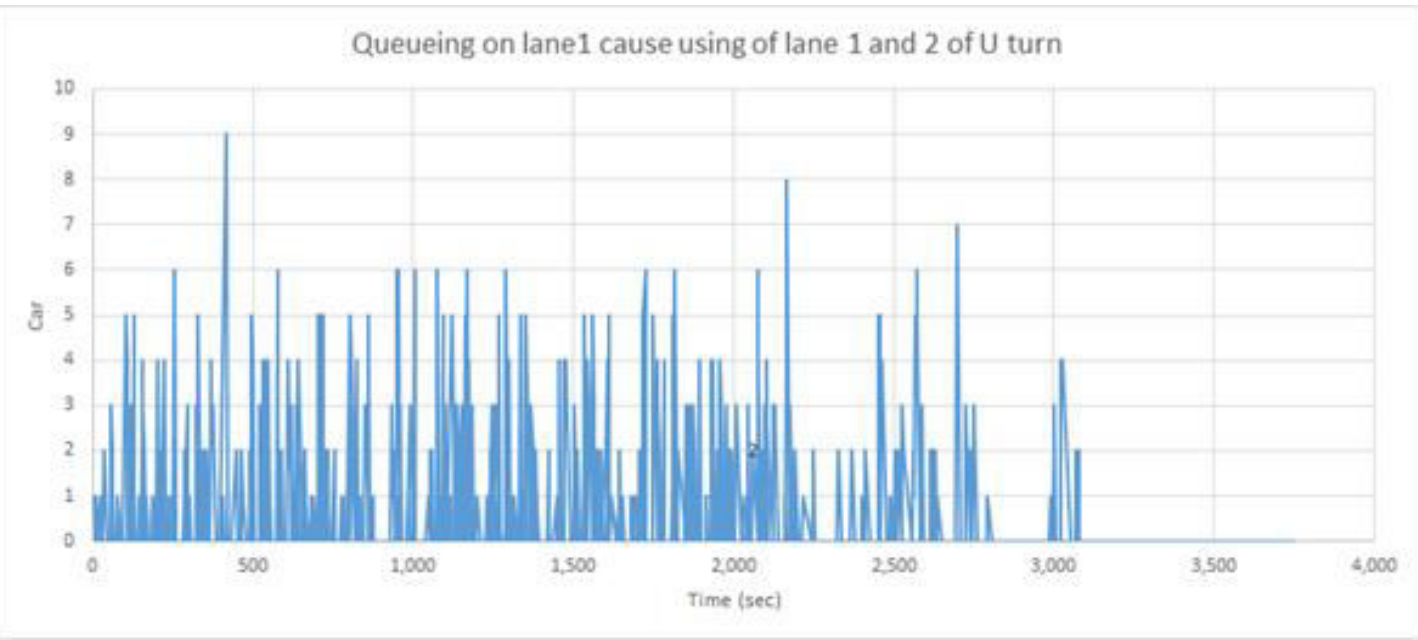

Figure 6. Graph of Queueing on lane1 cause using of lane 1 and 2 of $U$ turn

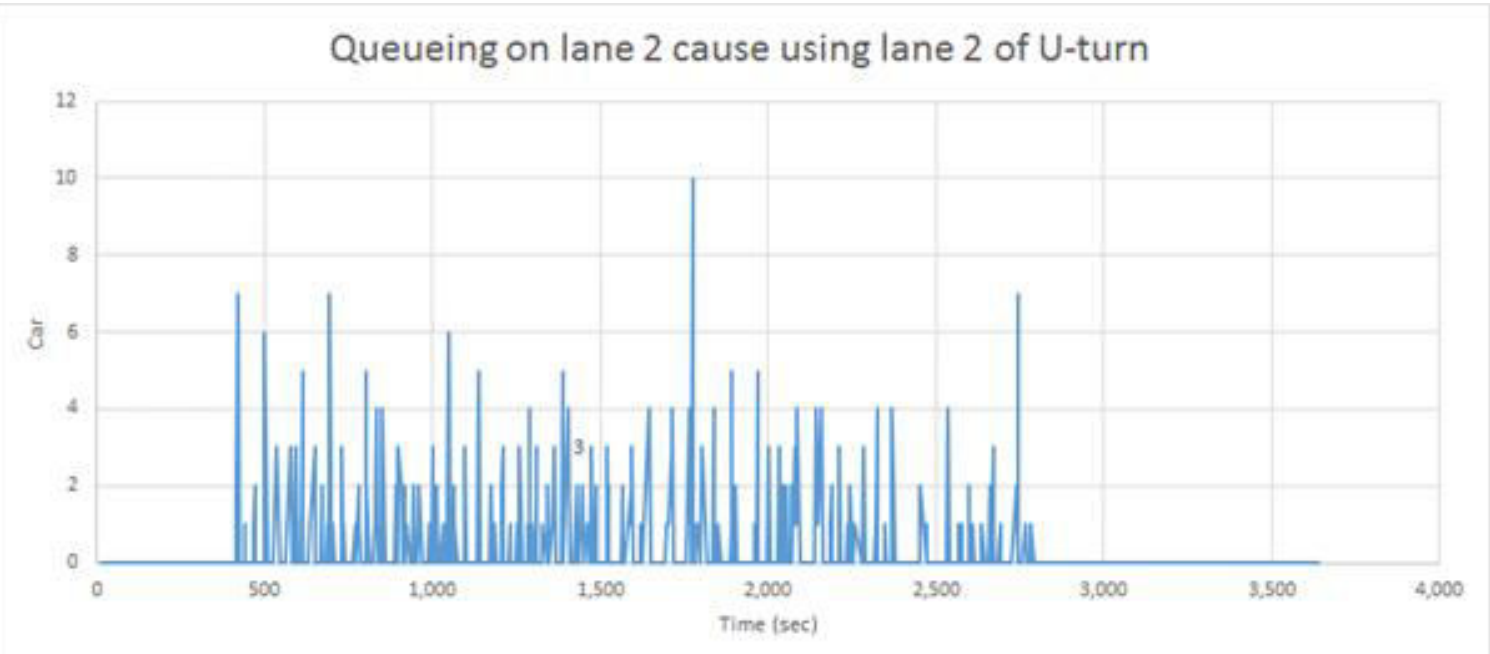

Figure 7. Queueing on lane 2 cause using lane 2 of U-turn

Design, 1990)

\section{CONCLUSION}

The conclusion is the maximum length of queueing cause impact of U-turn is 60 meters or 10 cars. The maximum length is occurred at lane 2 cause using lane 2 to turn $\mathrm{U}$. The reduction of distance U-turn and intersection is about 202 meters into 142 meters. That means, the distance still fulfils the minimum requirement of distance. This research shown that the importance determines location of U-turn facility by consider the possibility of queueing length.

The disadvantage of this research is not predicted the impact of queueing for intersection performance. Because the reduction distance is still fulfilled the minimum requirement.

\section{REFERENCES}

[1] May, Traffic Flow Fundamental. Prentice-Hall,
[2] Asmoro. Djoko, "Tata Cara Perencanaan Pemisah," Direktorat Jendral Bina Marga No. 14/T/BNKT/1990, 1990.

[3] Hadid et. al, "A Suggested Model to Simulate Storage Lane for Vehicle Queue on Urban Road U-Turn (Study Case: Middle East Ring Road, Surabaya)", ARPN Journal of Engineering and Applied Sciences, vol. 11 No. 24, pp. 14391-14397, Des. 2016.

[4] Hadid et. al, "Simulasi Antrian Kendaraan Akibat Tidak Efisiennya Jalur Perlambatan pada U-Turn Jalan Perkotaan", presented at Regional Conf. Aplikasi Teknologi Prasarana Wilayah, Surabaya, Indonesia, 2014.

[5] Hadid et. al, "Simulasi Antrian Kendaraan pada U-turn dan Dampak Terhadap Kinerja Jalan Perkotaan", presented at $17^{\text {th }}$ International Symposium FSTPT-17, Jember, Indonesia, 2014

[6] H. Muhammad, "Simulation of Vehicle Queueing on Peak Hour Impact of Pelican Crossing using Poisson Process", presented at $19^{\text {th }}$ International Symposium of FSTPT, Yogyakarta, Indonesia, 2016. 